\title{
Bio-Valorization of Physical and Chemical Pretreated Switchgrass on Volatile Fatty Acid Production
}

\author{
Sakthivel $\mathbf{U}^{1,2 *}$ \\ ${ }^{1}$ Department of Civil Engineering, National Institute of \\ Technology, Karnataka, India \\ ${ }^{2}$ Department of Civil Engineering, National Institute of \\ Technology, Tiruchirapalli, India \\ *Corresponding author: Uma Sakthivel, Research \\ Scholar, Department of Civil Engineering, National \\ Institute of Technology, Karnataka, India; Post-Doctoral \\ Fellow, Department of Civil Engineering, National \\ Institute of Technology, Tiruchirapalli, India
}

Received: May 20, 2021; Accepted: J une 18, 2021; Published: June 25, 2021

\section{Introduction}

Lignocellulosic biomass have been considered as main source of biofuel production due to its availability, no competent with agricultural resources, high carbohydrates content and high vitality [1]. Biomass consist of cellulose, hemicellulose and lignin were present as complex structure. Consequently, convert biomass to fuels and chemical are the valuable approach with low cost technology. However, presence of hard structure of lignin leads to obstacle to accessible cellulose and hemicellulose conversion to carbohydrates. The conversion of rice straw to ethanol using fermentation have been studied [2] whereas lignocellulosic biomass hydrolyzed to sugars and fermented to ethanol. Unfortunately, this process was more costly including production cost [1].

The most important obstacles were utilizing the biomass for product conversion in complex form. The resistance present in biomass and chemical bonding associated with each complex structure to the access of microorganisms and enzymes for proficient digestion [3]. The most resistant part of biomasses is presence of lignin due to hydrophobic nature. Inefficient biodegradation results in less solubility during hydrolysis stage of digestion. Improved degradation of cellulose and hemicellulose results in well-organized hydrolysis of biomass [4]. This imposes the needs to develop overall efficiency of digestion process [3]. The hydrolysis rates are enhanced by pretreating the substrates before feeding into digester.

Pretreatment was most significant process of digestion especially lignocellulosic biomass and it can be classified as physico-chemical and biological methods $[1,5]$. The chemical pretreatments have been considered as modest and operational method. Numerous chemicals such as acid, alkalis, gases, alcohols, and other reagents were used for pretreatment. Among these chemical pretreatment, numerous biomass sources were used, for example switchgrass, corn stover, hard woods and soft woods etc [6-8].

Discarded biomass or lignocellulosic waste could be converted into biofuels through the biological process. The biological processes utilize bacteria to convert biomass into biofuels called as anaerobic digestion [9]. It converts to byproduct as methane and/or fermented into sugars. Anaerobic Digestion used as a practice for bioenergy production through biological matter decomposition, greenhouse gas emission and deactivation of pathogens [10].

The numerous physico-chemical pretreatment conditions upset the production of methane potential and inhibition of bacterial action by each substrate or product by increasing concentration. For instance, VFAs concentration causes inhibition for methanogens [11]. During these conditions, it was difficult to remove volatile acids and hydrogen produced during digestion process. The acid accumulation reduces the buffering capacity and lowering of $\mathrm{pH}$ occur leads to hydrolysis/acidogenesis phase [12]. The accumulation VFA leads to decrease in hydrolysis rate of solids by microbial population $[1,10]$.

The VFA was most important parameter for control of anaerobic digestion. The VFA was good process indicator and ability to reflect on metabolic stage of system [12]. The relative changes in system of parameter were significant compared with uncertainties [13]. The accumulation of VFA reflects on coupling between acid producer and consumer. Higher acetate concentration provides imbalance to system. Propionate shows better indicator of process stability. The stability of system depends on propionate to acetate ratio as process indicator. The compounds iso-butyrate or iso-valerate concentration below $0.06 \mathrm{mM}$ indicates constant processes. It could be concluded that feasibility of VFA level indicates the state of process. The different system have normal effects of VFA based on composition of substrates used for anaerobic digestion or by operating conditions [13-17]. The VFA production from lignocellulosic materials, sludge and biodegradable organic matter are the important intermediates through digestion. It offers feasible platform for value addition in form of salts of carboxylic acids converted to chemical compounds [18]. The process was more intensive due to anaerobic processes as well as biotechnological applications.

The switchgrass were used for the production of VFA for the present study. Switchgrass was most commonly available perennial 
crop in Western Ghats of Karnataka which grows in faster rate. These Crops were found at most of the places near to road side. Crops also extensive and attracts attention as biofuels $[1,19]$. The current work investigates (1) by applying physical and chemical pretreatment of switch grass (2) the effects of VFAs on pretreated switchgrass in batch digestion systems.

\section{Materials and Methods}

\section{Sample collection}

The feedstock used for the present study was switchgrass. Switchgrass collected from National Institute of Technology Karnataka Mangalore, India. The collected substrate could be reduced its size by making into pieces approx. of $10-15 \mathrm{~cm}$ using chopper and dried at hot air oven for 6 hours at $110^{\circ} \mathrm{C}$ to reduce the moisture content. The dried biomass ground its size with mixer grinder and sieve through $0.45 \mu \mathrm{m}$ to maintain uniformity. The biomass was stored at ambient temperature until further use. The initial characteristics of materials were mentioned in Table 1 .

\section{Pretreatment of switchgrass}

The pretreatment applied for switchgrass to access the component of cellulose and hemicellulose. The pretreatment adopted for switchgrass are physical and chemical methods which are Thermal (TT), Hot Water (HW), dilute acid (AT), dilute $\mathrm{NaOH}$ (ALT), and Organosolv (OG) treatments. Pretreatments carried out with the $5 \%$ solid loading ratios [20]. A $5 \mathrm{~g}$ of dry materials used with $1 \%$ concentration and reaction temperature was fixed (Table 2). The liquid and solid phases were segregated after pretreatment with vaccum filtration. The solid phases were washed away with deionized water and dried up at $110^{\circ} \mathrm{C}$ for further analysis.

\section{Experimental methods}

The anaerobic sludge was taken from Bikampady industrial area Karnataka, India and stored at refrigeration below $5^{\circ} \mathrm{C}$. The digestions were carried with Duran Schott reactor with operational volume

Table 1: Characteristics of switchgrass and Innocum.

Table 1: Characteristics of switchgrass and Innocum.
\begin{tabular}{|l|c|c|}
\hline \multicolumn{1}{|c|}{ Parameter } & Units & Value \\
\hline Switchgrass & $\%$ & 96.49 \\
\hline Total solids & $\%$ & 88.12 \\
\hline Volatile solids & $\%$ & \\
\hline Anaerobic Sludge & $\%$ & 9.53 \\
\hline Total solids & $\%$ & 6.56 \\
\hline Volatile solids & $\mathrm{g} / \mathrm{L}$ & 3.168 \\
\hline COD & & \\
\hline
\end{tabular}

Table 2: Pretreatment conditions for switchgrass.

\begin{tabular}{|c|c|c|c|}
\hline S. No. & Pretreatment & Conditions (\%) & References \\
\hline 1 & Raw & NA & - \\
\hline 2 & Acid & $1 \%$ for $60 \mathrm{~min}$ & {$[35]$} \\
\hline 3 & Alkaline & $1 \%$ for $24 \mathrm{hrs}$ & {$[36]$} \\
\hline 4 & Hot water & $121^{\circ} \mathrm{C}$ for $60 \mathrm{~min}$ & {$[37]$} \\
\hline 5 & Thermal & $121^{\circ} \mathrm{C}$ for $15 \mathrm{~min}$ & {$[38]$} \\
\hline 6 & Organosolv & $\begin{array}{c}1 \% \mathrm{H}_{2} \mathrm{SO}_{4}(\mathrm{w} / \mathrm{w})+75 \% \text { Aq. Ethanol for } \\
60 \mathrm{~min}\end{array}$ & {$[39]$} \\
\hline
\end{tabular}

NA: Not Applicable. of $500 \mathrm{ml}$. The medium contains $5 \mathrm{~g} / \mathrm{L}$ of pretreated switchgrass and $495 \mathrm{ml}$ of inoculum was used. The sodium bicarbonate solution were used as alkaline buffer [16]. The experiments were conducted at $35^{\circ} \mathrm{C}$ batch mode aimed at 31 days in one liter digester that were vacuumpacked with silicone rubber stopper. The digesters were purged with nitrogen gas for maintaining anaerobic environment when it was opened for sample.

\section{Experimental procedure}

The experiments of anaerobic digestion of raw and pretreated switchgrass in batch reactor were conducted for VFA production. The bioreactors were worked under mesophilic conditions and maintaining of optimum $\mathrm{pH}$. The Duran Schott bottles with silicone stopper were used as bioreactor and sampling port at the top. The bioreactors were closed with silicone rubber stopper for the removal of biogas and for regulating the $\mathrm{pH}$ respectively. The temperature of bioreactor were maintained by heating mantle which had an accuracy of $34^{\circ} \mathrm{C} \pm 2^{\circ} \mathrm{C}$ and measured by thermometer ranges from $0-80^{\circ} \mathrm{C}$ with the accuracy of $0.2^{\circ} \mathrm{C}$. The substrates having different TS concentration calculated as the weight of solids to total volume of solids and water content expressed in terms of solids approximately equal to mass of water.

All the bioreactors were operated by fed with activated sludge i.e., inoculum. The experiments were carried out for 32 days digestion period. The liquid samples were collected with syringe from each reactor periodically for determining process parameters which are $\mathrm{pH}$ and VFA composition. The substrates were mixed once every day when the gas was measured at a particular time. The mixing of digester maintains neighboring contact between microorganisms and the substrate [21].

\section{Process parameters}

Volatile fatty acid: The compositional VFA analysis was analyzed using Gas Chromatography (GC) periodically.

Instruments: The thermo Trace GC-FID system was used with BP 21 column (length $30 \mathrm{~m}$, internal diameter of $0.3 \mathrm{~mm}$ and film thickness of $0.25 \mathrm{~mm}$ ) packed with spherocarb. The nitrogen was used as carrier gas with the flow rate of $2 \mathrm{ml} / \mathrm{min}$. the detector and injector port were maintained at temperature of $210^{\circ} \mathrm{C}$ and $220^{\circ} \mathrm{C}$. The performance of runs using the temperature programme consist of isothermal period of $80^{\circ} \mathrm{C}$ for 5 minutes followed by a $10^{\circ} \mathrm{C}$ minimum temperature upgrade to $120^{\circ} \mathrm{C}$, a subsequent temperature gradient of $6^{\circ} \mathrm{C} / \mathrm{min}$ to $180^{\circ} \mathrm{C}$ and 1 minute isotherm period at $220^{\circ} \mathrm{C}$. The column used with flow rate and the temperature encoding shows well-separation of peaks [22].

Sample preparation: The samples used for analysis were acidified with $65 \%$ nitric acid to maintain $\mathrm{pH}$ around 2 . The equal volume aliquot of acidified samples was mix well with diethyl ether. The supernant of ether phase was transferred to volumetric phase. The volume of ether phase extracted upto $1 \mathrm{ml}$ by the adding small quantity of magnesium sulphate to absorb the drops of moisture. The extract was allowed to cool for 10 minutes in refrigeration and transferred to vials and closed tightly. The $5 \mu \mathrm{l}$ volume of extract was injected into GC with syringe. The extracts can be stored at ambient temperature for a week [22,23].

Calibration of VFA Standards: The sequence of VFA standards 
for the standardization curves were obtained with VFA mixture in the concentration range from $0-10 \mathrm{mM}$. The VFA standard mix with C2-C7 purchased from Supelco Company. The subsequent VFA compounds were analyzed: acetic acid, propionic acid, iso-butyric acid, butyric acid, iso-valeric acid, butyric acid and hexanoic acid from the sample with flow rate of $2 \mathrm{~mL} / \mathrm{min}$ and compared with the standards [24].

Solids concentration: The total and volatile solid concentrations were determined based on standard method [25]. The solids were determination by the gravimetric methods with known quantity of samples. The solids concentration plays a role of microbial activities and also the production of VFA [26].

Chemical oxygen demand (COD) determination: The total COD determination of the sample by closed reflux digestion method from APHA [25]. The known quantity of sample digested with acid reagent and chromate solution for two hours. The digested samples were cooled down to optimum temperature and titrated with ferrous ammonium sulphate to determine for concordant value and calculated.

\section{Results and Discussion}

\section{Characteristics of switchgrass}

The characteristics of switchgrass were analyzed to check the suitability towards anaerobic digestion processes as mentioned in Table 3. The parameters such as $\mathrm{pH}, \mathrm{VFA}$ and lignin degradation were examined for this present study.

The $\mathrm{pH}$ in the anaerobic bioreactor was the utility of retention time. During initial stage of digestion, large amount of organic acid were produced at initial stages by acid forming bacteria, the $\mathrm{pH}$ maintained in the digester were reduced to below 5 . The digestion continues, increase in ammonia concentration increases the digestion of nitrogen, leads to increase in $\mathrm{pH}$ till 7.5 to 8.0 [27].

The VFA production occurs during the fermentation under low $\mathrm{pH}$ condition. These reasons are due to microbial metabolism or by hydrogen production [12]. The total VFA observed at the initial stage for the substrate were 3-4 g/Kg and 4-5 g/ $\mathrm{kg}$ at the end of digestion. This study confirms that variation in $\mathrm{pH}$ during digestion gradual increase in VFA concentration [12]. The effects of VFA concentration were observed with the lignin degradation. The VFA profiles varies with the different pretreatment and its lignin degradation.

The lignin degradation using physicochemical pretreatments were studied for accessibility of substrate depends on solubility, molecular weight and structural composition [28]. The influences of interaction of microorganism and lignin were observed with pretreatments. The degradation with pretreatment ranges from $6 \%$ to $9 \%$ was observed from the present study.

Table 3: Compositional Analysis of Raw and pretreated switchgrass.

Table 3: Compositional Analysis of Raw and pretreated switchgrass.
\begin{tabular}{|c|c|c|c|c|c|c|c|c|}
\hline \multirow{2}{*}{ S. No. } & $\begin{array}{c}\text { Process } \\
\text { Parameters }\end{array}$ & Raw SG & \multicolumn{5}{|c|}{ Pretreated SG } \\
\cline { 5 - 9 } & AT & ALT & OG & HW & TT & UT \\
\hline 1 & 7.02 & 7.38 & 7.49 & 5.97 & 7.64 & 7.11 & 6.71 \\
\hline 2 & $\begin{array}{c}\text { Total VFA: Initial } \\
\text { (g/kg) }\end{array}$ & - & 4.02 & 4.23 & 4.22 & 4.42 & 3.48 & 3.83 \\
\hline 3 & $\begin{array}{c}\text { Total VFA: Final } \\
\text { (g/kg) }\end{array}$ & - & 5.03 & 5.27 & 5.27 & 5.53 & 4.35 & 4.78 \\
\hline
\end{tabular}

\section{Overview of volatile acid concentration from pretreated switchgrass}

The VFA profiles were observed with pretreated switchgrass during anaerobic digestion. The profile shows variation with the different pretreatments in the first 10 days, afterwards it was gradually reduced. The VFA of pretreated sample maintained with stability after 10 days were observed. The effect indicates on pretreatment of VFA production decreases over the period of time. Contrastingly the effect of pretreatment does not shows any effect on VFA production which indicates pretreatment could not inhibit the acidogenic and acetogenic stages of digestion. Similarly study on VFA production with pretreatment for lawn grass were observed by [3].

\section{Various volatile acid profiles}

Figure 1 describes about the effect of different pretreatment on VFA production was observed for 30 days digestion period. The intermediate VFA compounds such as acetic acid, propionic acid, butyric acid, isovaleric acid, isobutyric acid and hexanoic acid are produced and further converted to acetate, propionate, i-butyrate, butyrate, i-valerate and hexonate due to its solubility nature of oxygen demand [29]. The VFA concentrations were observed as per the preceding order: acetic acid $>$ butyric acid $>$ iso-valeric acid $>$ propionic acid. This data showed that acetic acid was the major component when compared with other fatty acids during the digestion process. Majorly acetic acid was produced and further converted to acetate due to microbial metabolism [30]. These fatty acids conversion confirms that decomposition of solid organic matter takes place by anaerobic microorganisms which increases the digestion time. Conversion of solid organic materials into soluble organic compounds increases the solubility during various fatty acid compounds. Hydrolysis and fermentation occur in a faster rate for the pretreated switchgrass was observed and further it was lowered from day 20 onwards with least consumption rate of microorganism to produce acids. This was due to rapid decomposition by facultative bacteria $[12,26]$. The commercial applications of compositional VFAs operation produced from digestion were discussed in following sections.

\section{Effects of physical and chemical pretreatment on volatile fatty acids production}

Acetic acids are the one of the major compounds produced during anaerobic digestion. The application of acetic acid was extensively used in chemical industry for vinegar and ester production and

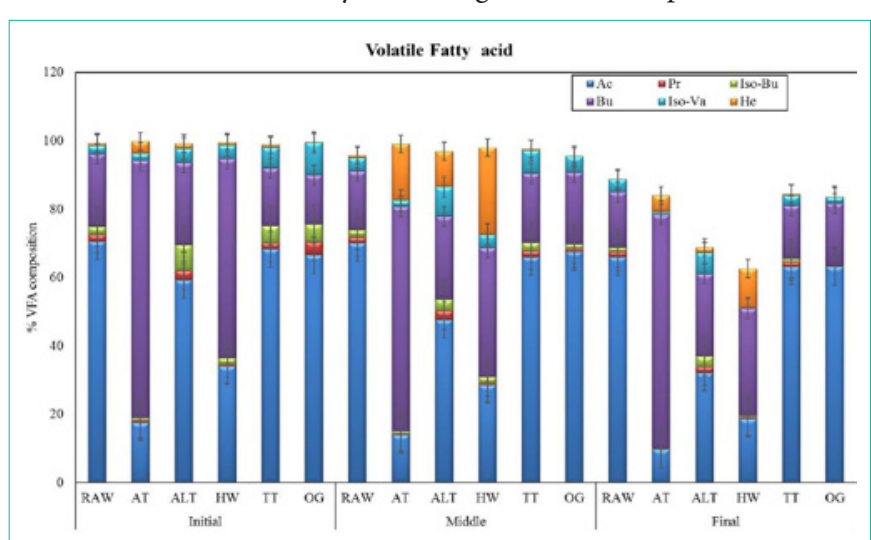

Figure 1: Volatile fatty acid compositions produced from pretreated switchgrass by batch anaerobic digestion. 


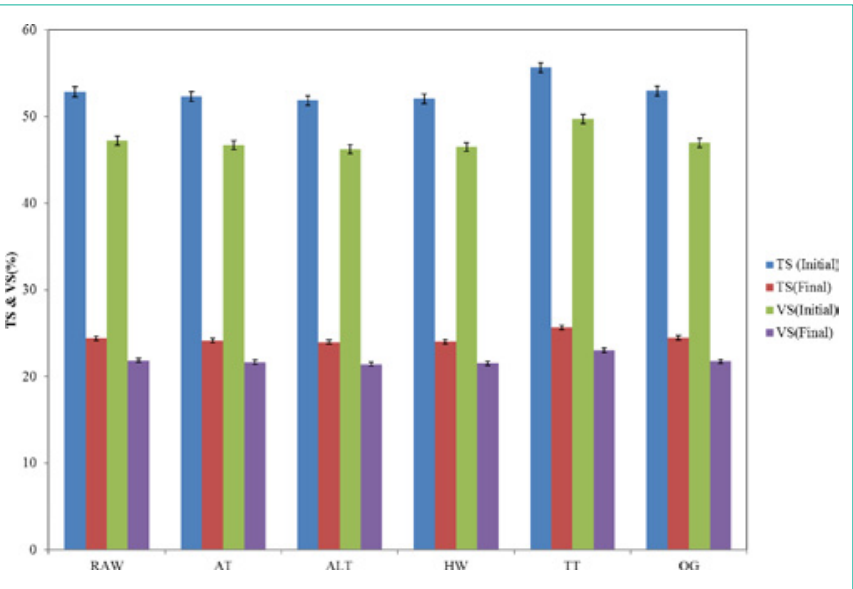

Figure 2: Variation of total and volatile solids concentration of raw and pretreated SG (AT: Acid treated SG; ALT: Alkaline treated SG; HW: Hot water treated SG; TT: Thermal treated SG; OG: Organosolv treated SG).

also used as a solvent in some industries. The acetic acid profile of pretreated switchgrass was depicted in Figure 2. In anaerobic digestion process, the group of anaerobic bacteria directly converts into carbohydrate and further converted into acetic acid. Average acetic acid concentration produced from RAW, AT, ALT, HW, TT and OG are $68.84 \%, 13.72 \%, 46.35 \%, 27.07 \%, 65.81 \%$ and $65.70 \%$ respectively. The highest acetic acid production was observed from RAW; TT and OG pretreated switchgrass, which may be possible and favourable conditions for converting into methane during methanogenesis that is inversely proportional to volatile acid production. In later stages, possibly the volatile acid production can be converted to methane when digestion continues with favourable anaerobic environment. The other pretreated SG (AT, ALT, HW) was observed with least acetic acid was produced in batch digestion. A gradual decrease in acetic acid was witnessed with pretreated SG after the $15^{\text {th }}$ day and increases in performance were obtained.

Propionic acid was produced from amino acids by metabolic break down of fatty acid contains odd number of carbon atoms respectively. The presence of propionic acids could degrade the complex organic compound in the anaerobic environment. The application of propionate could be used as a preservative in bakes production. The propionic acid observed for raw and pretreated switchgrass are $1.75 \%, 0.30 \%, 2.34 \%, 0.50 \%, 1.65 \%$, and $1.64 \%$ respectively. The gradual decrease in propionate composition were observed with OG pretreated switchgrass and increase with TT and RAW switchgrass after $15^{\text {th }}$ day herewith respectively, which represents the production of volatile acids from complex structure of lignocellulosic biomass [26].

The butyric acid produced and occurs in the form of ester like fats. Butyric acid holds the second highest production during digestion. This acid could be used in a fermenter for starch preparation as well as sugar industrial for neutralization processes. The butyric acid concentration $18.18 \%, 69.82 \%, 24.21 \%, 42.42 \%, 17.51 \%$, and $11.19 \%$ are observed from raw and pretreated switchgrass. The higher butyric acid concentration leads to an inhibition of methanogenesis. Butyric acid production occurs during hydrolysis stage which leads to unpleasant smell and odour. The presence of butyric acid can inhibit acidogenesis phase and performance may get affected [31].
The iso-valeric acid concentration observed with RAW, AT, ALT, HW, TT and OG treated switchgrass are $3.41 \%, 1.59 \%, 6.27 \%, 2.72 \%$, $5.27 \%$ and $4.11 \%$ respectively. The gradual decrease of Iso-Valerate occurs with TT, OG and HW were observed. With ALT, I-valerate decreases until day 10 and further increases gradually till the end of digestion which was possibly due to the presence of complex compounds as well as with its pretreatment condition of switchgrass. The Iso-Valerate present in the digester indicate the imbalance in the digester caused by the presence of hydrogen [32]. The iso-valeric acid was used in the industrial application as to solubilize organic compound and also used as a solvent respectively.

The iso-butyric acid concentration of raw and pretreated switchgrass are $1.93 \%, 0.59 \%, 4.62 \%, 1.41 \%, 2.85 \%$ and $2.10 \%$ observed with batch digestion. A similar trend of decrease was observed with all the pretreated switchgrass and raw switchgrass except ALT like other volatile fatty acids. This Iso-Butyrate can be produced artificially with the help of alkalis ions. This present study confirms that the presence of alkali ions increases iso-butyric acid concentration when compared with other pretreatments. The solubility of iso-butyrate was higher in water which can improve the greater utilization of carbohydrate increases the metabolism rate during digestion [33].

The hexanoic acid observed with RAW, AT, ALT, HW, TT and OG treated switchgrass $0.51 \%, 8.29 \%, 4.49 \%, 12.57 \%, 0.60 \%$ and $0.33 \%$ was observed. The steady increases in these acids were observed with HW, AT and ALT switchgrass. The trace levels of hexonate were observed with other pretreatments which does not make much change in the digestion process. Hexanoic acids are colourless compound found as fat in animals. The applications of these compounds are used in the manufacturing of esters of artificial flavours. The trace levels of compounds were used for the value-added products.

\section{Effects of solids concentration on the performance of batch digestion}

The effect of solids (total and volatile) represents the production of fatty acids from anaerobic digester. The initial total and volatile solids of $50 \%$ volume of the digester was about $53 \%$ from all the digesters at initial stage as in which different pretreatment methods were adopted for switchgrass. Even though, after pretreatment, removal efficiency which was observed as $50 \%$ of conversion to endproducts was observed in this study. The switchgrass was considered as a slow biodegradable feedstock due to which the pretreatment was applied are acid, alkaline, hot water, thermal and organosolv methods for a faster rate of conversion to final products. The results observed at the end of digestion approximately $25 \%$ of reduction for both total and volatile solids. However, it was $50 \%$ of transformation followed with switchgrass even after pretreatment leads to the production of VFA and biogas as well. In overall, there was a gradual reduction in the solids concentration was obtained during 30 days anaerobic digestion. There was no significant observation in solids degradation for the pretreated substrate and raw switchgrass until the end of digestion. The reduction in solids concentration was attained due to the degradation of organic matter [34].

\section{Effects of $\mathrm{pH}$ on batch digestion performance and its focus on inhibition studies}

The inhibition study characterizes the nature of volatile fatty acid production during digestion. The result of individual VFA compounds 


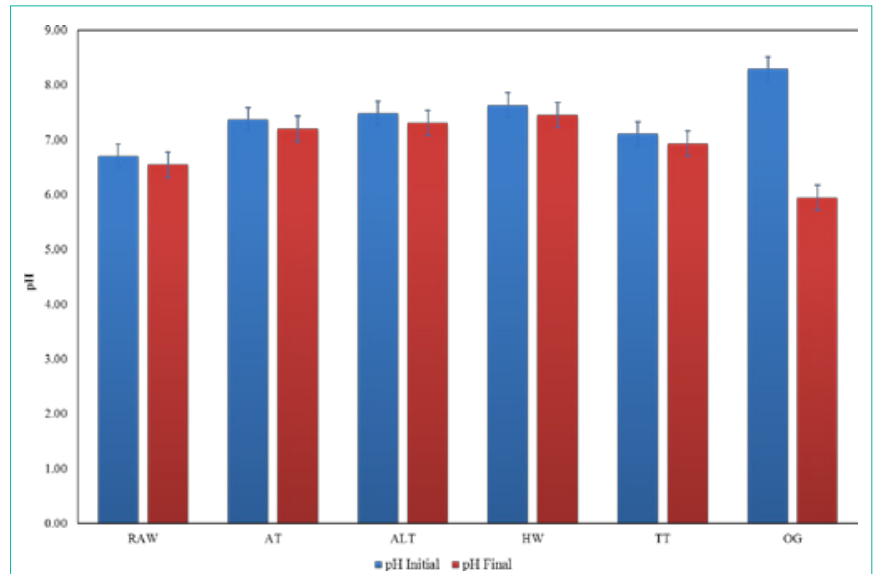

Figure 3: $\mathrm{pH}$ Variations during the process of digestion.

shows different trends with physical and chemical pretreatment conditions. Therefore, chemical pretreatment conducted with less than $1 \%$ of chemicals resulted in fewer changes in the production of VFA compared with raw SG. The role of $\mathrm{pH}$ plays a major part in which inhibitors was considered in anaerobic digestion. Hence, it was mandated to adjust $\mathrm{pH}$ for reducing inhibition during anaerobic digestion, which in turn affects the VFA production. The $\mathrm{pH}$ was monitored for the entire digestion process to evaluate the performance of digestion. Figure 3 depicted the average $\mathrm{pH}$ is monitored during entire process. This present study concentrates on VFA production with its application of value- added products. The low $\mathrm{pHs}$ resulting in the production of VFA which had a strong impact on methanogens respectively. To produce higher methane yield, $\mathrm{pH}$ maintenance could be optimum. The adjustment of $\mathrm{pH}$ was the major play role of inhibitors greatly affects the production of VFA [16].

The $\mathrm{pH}$ data obtained show the acidic range before the start-up of experiments which was assumed to be stable. Further $\mathrm{pH}$ was changed to neutral range during the $15^{\text {th }}$ day that was $\mathrm{pH}$ as 6.8 and remained within the range of 7.0-8.0 throughout the fermentation process The initial drop in $\mathrm{pH}$ are occurred due to the activity of microbes initiated to consuming substrates in the fermentation process which are essential to produce volatile fatty acids. The process parameter $\mathrm{pH}$ increases results in increases in ammonia and volatile acid leads the working of the digester in the steady state during the digestion. The fluctuation of $\mathrm{pH}$ leads the digester significantly affected the growth rate of the acidogenesis to methanogenesis stages of digestion. The average range of $\mathrm{pH}$ as 6.0 to 7.3 was recorded at the end of the digestion period.

\section{Conclusions}

The results showed that maximum acetic acid produced from raw switchgrass compared with pretreated biomass. The result reveals that maximum $69 \%$ acetic acid obtained with raw switchgrass and least of $14 \%$ was observed with acid pretreated SG respectively. Similarly, butyric acid concentration shows the highest as $70 \%$ for AT and least as $12 \%$ for OG switchgrass. Acetic acid and butyric acid concentration were highest above 50\%; other volatile fatty acids showed the least production which is below 5\% respectively. From the application point of view, the concentration above $50 \%$ could be considered and utilized for the chemical industries. This study concludes that, bio- based lignocellulosic biomass can be utilized for producing acetate and butyrate which can be used as a solvent by chemical industrial applications.

\section{Acknowledgement}

I would like to thank Environmental Engineering Laboratory, National Institute of Technology Karnataka for providing me the facility to carry out this research work. Also, I am thankful to acknowledge the supports provided by Environmental Engineering Teams for this research work.

\section{References}

1. Kim N, Park GW, Kang J, Kim Y, Chang HN. Volatile Fatty Acid Production from Lignocellulosic Biomass by Lime Pretreatment and Its Applications to Industrial Biotechnology. Biotechnol Bioprocess Eng. 2013; 18: 1163-1168.

2. Cheng YS, Zheng Y, Yu CW, Dooley TM, Jenkins BM, Vandergheynst JS. Evaluation of high solids alkaline pretreatment of rice straw. Appl Biochem Biotechnol. 2010; 162: 1768-1784

3. Yu L, Bule M, Ma J, Zhao Q, Frear C, Chen S. Enhancing volatile fatty acid (VFA) and bio-methane production from lawn grass with pretreatment. Bioresour Technol. 2014; 162: 243-249.

4. Chang HN, Kim NJ, Kang J, Jeong CM. Biomass-derived volatile fatty acid platform for fuels and chemicals. Biotechnol Bioprocess Eng. 2010; 15: 1-10.

5. Kato DM, Elia N, Flythe M, Lynn BC. Pretreatment of lignocellulosic biomass using Fenton chemistry. Bioresour Technol. 2014;1 62: 273-278.

6. Silverstein RA, Chen Y, Sharma-Shivappa RR, Boyette MD, Osborne J. A comparison of chemical pretreatment methods for improving saccharification of cotton stalks. Bioresour Technol. 2007; 98: 3000-3011.

7. Harmsen P, Huijgen W, Bermudez L, Bakker R. Literature Review of Physical and Chemical Pretreatment Processes for Lignocellulosic Biomass. Energy. 2010.

8. Sambusiti C, Ficara E, Malpei F, Steyer JP, Carrère H. Effect of sodium hydroxide pretreatment on physical, chemical characteristics and methane production of five varieties of sorghum. Energy. 2013; 55: 449-456.

9. Mussoline W, Esposito G, Giordano A, Lens P, Mussoline W, Esposito G. Technology The Anaerobic Digestion of Rice Straw: A Review. 2015; 3389.

10. Huang W, Huang W, Yuan T, Zhao Z, Cai W, Zhang Z, et al. Volatile fatty acids (VFAs) production from swine manure through short-term dry anaerobic digestion and its separation from nitrogen and phosphorus resources in the digestate. Water Res. 2016; 90: 344-353.

11. Siegert I, Banks C. The effect of volatile fatty acid additions on the anaerobic digestion of cellulose and glucose in batch reactors. 2005; 40: 3412-3418.

12. Wang K, Yin J, Shen D, Li N. Anaerobic digestion of food waste for volatile fatty acids (VFAs) production with different types of inoculum: Effect of $\mathrm{pH}$. Bioresour Technol. 2014; 161: 395-401.

13. Ahring BK, Sandberg M, Angelidaki I. Volatile fatty acids as indicators of process imbalance in anaerobic digestors. Appl Microbiol Biotechnol. 1995; 43: 559-565.

14. Ahn HK, Smith MC, Kondrad SL, White JW. Evaluation of biogas production potential by dry anaerobic digestion of switchgrass-animal manure mixtures. Appl Biochem Biotechnol. 2010; 160: 965-975.

15. Yang L, Li Y. Anaerobic digestion of giant reed for methane production. Bioresour Technol. 2014; 171: 233-239.

16. Park GW, Kim I, Jung K, Seo C, Han JI, Chang HN, et al. Enhancement of volatile fatty acids production from rice straw via anaerobic digestion with chemical pretreatment. Bioprocess Biosyst Eng. 2015; 38: 1623-1627.

17. Xu Q, Tian Y, Wang S, Ko JH. A comparative study of leachate quality and biogas generation in simulated anaerobic and hybrid bioreactors. Waste Manag. 2015; 41: 94-100. 
18. Singhania RR, Patel AK, Christophe G, Fontanille P, Larroche C. Bioresource Technology Biological upgrading of volatile fatty acids, key intermediates for the valorization of biowaste through dark anaerobic fermentation. Bioresour Technol. 2013; 145: 166-174.

19. Zabed H, Sahu JN, Boyce AN, Faruq G. Fuel ethanol production from lignocellulosic biomass: An overview on feedstocks and technological approaches. Renew Sustain Energy Rev. 2016; 66: 751-774.

20. Antonopoulou G, Lyberatos G. Effect of pretreatment of sweet sorghum biomass on methane generation. Waste and Biomass Valorization. 2013; 4 583-591.

21. Liu C, Yuan X. Prediction of methane yield at optimum $\mathrm{pH}$ for anaerobic digestion of organic fraction of municipal solid waste. 2008; 99: 882-888.

22. Manni G, Caron F. Calibration and determination of volatile fatty acids in waste leachates by gas chromatography. J Chromatogr. 1995; 690: 237-242.

23. Siedlecka EM, Kumirska J, Ossowski T, Glamowski P, Gołębiowski M Gajdus J, et al. Determination of Volatile Fatty Acids in Environmental Aqueous Samples. Polish J Env stud. 2008; 17: 351-356.

24. Appels L, Houtmeyers S, Degrève J, Impe J Van, Dewil R. Influence of microwave pre-treatment on sludge solubilization and pilot scale semicontinuous anaerobic digestion. Bioresour Technol. 2013; 128: 598-603.

25. APHA. Standard Methods for the Examination of Water and Wastewater. Am Water Work Assoc Water Environ Fed. 1999; 541.

26. Page LH, Ni J, Heber AJ, Mosier NS, Liu X, Joo H, et al. Characteristics of volatile fatty acids in stored dairy manure before and after anaerobic digestion. Biosyst Eng. 2013; 118: 16-28.

27. Macharia FN. Biogas production for domestic use. 2015: 1-51.

28. Barakat A, Monlau F, Steyer J, Carrere H. Effect of lignin-derived and furan compounds found in lignocellulosic hydrolysates on biomethane production. Bioresour Technol. 2012; 104: 90-99.

29. Wan S, Sun L, Douieb Y, Sun J, Luo W. Anaerobic digestion of municipal solid waste composed of food waste, wastepaper, and plastic in a single-stage system: Performance and microbial community structure characterization. Bioresour Technol. 2013; 146: 619-627.
30. Yu B, Shan A, Zhang D, Lou Z, Yuan H, Huang X, et al. Dosing time of ferric chloride to disinhibit the excessive volatile fatty acids in sludge thermophilic anaerobic digestion system. Bioresour Technol. 2015; 189: 154-161.

31. Zheng Z, Liu J, Yuan X, Wang X, Zhu W, Yang F, et al. Effect of dairy manure to switchgrass co- digestion ratio on methane production and the bacterial community in batch anaerobic digestion. Appl Energy. 2015; 151: 249-257.

32. Nordell E, Nilsson B, Nilsson S, Karisalmi K, Moestedt J. Co-digestion of manure and industrial waste - The effects of trace element addition. Waste Manag. 2016; 47: 21-27.

33. Weigand E, Young JW, McGilliard AD. Volatile fatty Acid Metabolism by Rumen Mucosa from Cattle Fed Hay or Grain. J Dairy Sci. 1974; 58: 12941300.

34. Pilli S, More T, Yan S, Dayal R, Surampalli RY. Anaerobic digestion of thermal pre-treated sludge at different solids concentrations e Computation of mass-energy balance and greenhouse gas emissions. J Environ Manage. 2015; 157: 250-261.

35. Cui M, Shen J. Effects of acid and alkaline pretreatments on the biohydrogen production from grass by anaerobic dark fermentation. Int J Hydrogen Energy. 2012; 37: 1120-1124.

36. Zhu J, Wan C, Li Y. Enhanced solid-state anaerobic digestion of corn stover by alkaline pretreatment. Bioresour Technol. 2010; 101: 7523-7528.

37. López González LM, Pereda Reyes I, Dewulf J, Budde J, Heiermann M Vervaeren $\mathrm{H}$. Effect of liquid hot water pre-treatment on sugarcane press mud methane yield. Bioresour Technol. 2014; 169: 284-290.

38. Çelik I, Demirer GN. Biogas production from pistachio (Pistacia vera L.) processing waste. Biocatal Agric Biotechnol. 2015; 4: 767-772.

39. Amiri H, Karimi K, Zilouei $H$. Organosolv pretreatment of rice straw for efficient acetone, butanol, and ethanol production. Bioresour Technol. 2014 152: 450-456. 